\title{
Technology use by pre-service teachers during teaching practice: Are new teachers embracing technology right away in their first teaching experience?
}

Tshepo Batane and Abraham Ngwako

University of Botswana

Equipping pre-service teachers with technology skills and knowledge is now regarded as a vital element of any teacher-training program so as to capacitate the new teachers to meet the educational demands of the twenty-first century. Therefore, it is important to establish whether these teachers do actually apply these skills when they first get to the field and if not, what could be the hindering factors. This study investigated technology use by pre-service teachers during teaching practice. The unified theory of acceptance and use of technology (UTAUT) was used as an evaluative framework for the study. Observations, interviews, and document analysis were used to collect data. The results indicated that the majority of the participants did not use technology in the delivery of their lessons, even though they reported high competency levels in the use of technology resources. The underlying reasons for this lack of technology use were identified. The results point to a need to develop a systematic and comprehensive strategy toward technology implementation involving all stakeholders to ensure a smooth transition for preservice teachers as they move from training to practice and to have technology use reinforced at all levels.

\section{Introduction}

Technology training has become an important component of many teacher training programs to ensure that aspiring teachers are well prepared to use technology in their teaching (Gülbahar, 2008). It is therefore important to establish whether these teachers do apply these skills once they get to the field or not. Teaching practice is the first platform that many pre-service teachers get to put into practice the skills they obtained during coursework of their programs. This is where the aspiring teachers first establish their own teaching philosophies and practices. In light of the changing learning landscape that is becoming more technology oriented, it is worth finding out if technology forms part of the teachers' repertoire right from the beginning. In the past, some studies suggested that the reason why most teachers were reluctant to use technology in their teaching was because it was neither part of their original training, nor part of their teaching when they first started to teach (Prensky, 2001; Rosenthal, 1999). As such, it was not easy for the teachers to adjust to new ways of doing things when technology was introduced. As Verloop, Van Driel and Meijer (2001) say, teacher cognitions take years to shape, therefore they cannot be easily changed. Nevertheless, technology has been identified as having potential to promote innovative teaching through providing an array of tools that can be used to facilitate learning (Almekhlafi \& Almeqdadi, 2010), hence it has become an important part of education.

Today, almost all teacher training programs around the world have a technology training component (Yüksel \& Kavanoz, 2011). Thus compared to their predecessors, the pre-service teachers of today are in a better position to make technology part of their teaching because of the training. These new teachers do not have to unlearn teaching habits which have been established over a long time. They could start off with innovative teaching techniques that support the use of technology. This is why it is essential to focus at that point where new teachers begin their teaching to establish whether they get off to a good start that could set them on the path to revolutionary teaching.

Most research studies on pre-service teachers' use of technology have focused on investigating teacher education programs to find out how much they prepare teachers to use technology in their teaching (Liu, 2012; Murley, Jukes, \& Stobaugh, 2013). Few studies have specifically observed pre-service teachers' transition as they move from colleges to the field, to establish whether they do put into use the skills and knowledge they obtained from the technology training programs. This study attempts to address this issue by investigating 
technology use by pre-service teachers during a teaching practice exercise, using a technology adoption theoretical framework. The rationale behind this study was that teaching practice is a field test for the aspiring teachers, therefore during this time they would display those abilities that they believe are required of them to be regarded as effective teachers. It is important to find out if technology forms part of this set of abilities because as Liu (2012) says, this process establishes the foundation for their future practices, so if technology is not included from the beginning, it may be difficult to add it at later stages.

\section{Background of the study}

The participants in this study were prospective teachers who were enrolled in a 1 year teacher training program known as the Post Graduate Diploma in Education (PGDE) at the University of Botswana. All students enrolled in this program have to take a compulsory course in educational technology. The main goal of the course is to explore classroom applications of various technologies, including the utilisation of the latest digital resources in learning. The course also explores various teaching and learning models that would help teachers to develop more effective instruction and emphasise pedagogical practices that promote technology integration in learning. The course provides students with opportunities to apply the learned skills through activities such as designing technology-based lesson plans, presentations, and developing various technology resources for their teaching.

As part of the requirements of the PGDE program, upon completion of course work, students have to engage in a teaching practice exercise for 7 weeks, where they get to teach in real life classrooms, and are assessed by both their mentors at the schools and the supervisors from the university. At the schools, the government took an initiative to make technology part of the education system through introducing computer studies subjects and also called for use of technology in all subjects across the curriculum. The purpose of this study then was to follow the pre-service teachers as they get to the schools to find out if they apply technology skills in their teaching and if not, establish what the hindering factors could be.

\section{Significance of the study}

The results of this study are crucial to stakeholders to help them identify discordant practices which impede technology uptake by pre-service teachers. This in turn would implore policy makers to create enabling circumstances that would facilitate implementation of skills and knowledge that pre-service teachers obtained during training. This study could also sensitise training institutions to make a conscious effort to infuse technology in their teaching and assessment frameworks so that its usage is not left to chance but is part of a holistic approach that promotes effective teaching.

\section{Literature review}

Teaching, in the twenty-first century has changed and requires teachers to be able to infuse technology resources in their lessons so as to meet today's literacy requirements (Kong et al., 2014). It therefore becomes crucial for new teachers to integrate technology in their teaching right away when they get to the field. Several studies have been conducted to investigate the level of technology use by pre-service teachers. The majority of the studies found that there is gross under-use of technology by pre-service teachers in the delivery of their lessons (Al-Ruz \& Khasawneh, 2011; Dawson, 2008; Liu, 2012). Most studies have attributed this lack of technology use to ineffective technology teacher training programs (Albirini, 2006; Liu, 2012; Scheeler, 2008). A commonly reported limitation of the training programs has been that they mainly provide students with the technology skills, but not how to effectively infuse technology in the curriculum (Oblinger \& Obliger, 2005; Wachira \& Keengwe, 2011). Effective training is believed to increase the competency levels of teachers in using technology (Koh \& Frick, 2009).

Improved competency levels in technology use have been linked to increased self-efficacy among teachers (Wang \& Wu, 2015), which, following Bandura's (1963) concept of social learning would in turn lead to increased usage of technology. A research study by Al-Ruz and Khasaweh (2011) which tested a model in which technology use of pre-service teachers was correlated with a number of university-based and school- 
based factors, reported that self-efficacy had the highest effect on technology integration. Similar findings were obtained by several other studies (Anderson \& Maninger, 2007; Koh \& Frick, 2009; Niederhauser \& Perkmen, 2010), which found that self-efficacy was the strongest predictor of pre-service teachers' intentions to use various software and willingness to use technology in their future classrooms. It is also worth noting that various studies have reported that there were no gender differences in terms of self-efficacy among teachers (Hargittai \& Shafer, 2006; Magliaro \& Ezeife, 2007; Teo, 2008).

Based on the findings of various studies, it is clear that increased self-efficacy in using technology will not lead to effective technology use if the teachers' pedagogical beliefs are not aligned with innovative teaching practices that promote technology use. A meta-analysis of literature by Ertmer (2005) to evaluate the relationship between teachers' pedagogical beliefs and their technology practices showed that it is pointless to try to change teachers' classroom practices without addressing their beliefs. However, as Ertmer also indicated, addressing this variable is a challenge because it deals with tacit phenomenon which may be difficult to verify except from people's actions. Chen (2008), for example, conducted a study to investigate the relationship between teachers' pedagogical beliefs and their technology integration and the findings showed a mismatch between what the teachers believed and their practices. Several other studies have noted similar observations and have attributed these inconsistencies to various factors such as, among other things, teachers' limited theoretical understanding, conflicting beliefs, and the school culture (Kelly-McHale, 2013; Nishino, 2012).

School cultures can enable or constrict technology uptake by teachers. School cultures encompass several elements such as school leadership's expectations, attitudes towards technology use, information and communication technology (ICT) support (both technical and pedagogical) and ICT policies. Al-Ruz and Khasawneh (2011), and Pelgrum and Law (2003), have gone as far as to say that school culture plays a bigger role in influencing teachers' use of technology than ICT skills. According to Allan, Law and Hong (2003), this is because if technology integration is part of the school culture, the teachers do not feel isolated in their attempts to use technology and support is available for them if they need it.

For new teachers, the inclinations by schools to adopt or not adopt a technology integration culture have an impact on their technology dispositions. As Inan and Lowther (2010) say, first years of teaching are characterised by new teachers learning how to become teachers and learning the culture of the school they find themselves in. In their 2005 study to identify challenges faced by beginning teachers, Conway, Micheel-Mays and Micheel-Mays identified issues of time and the need to be validated as some of the issues teachers deal with in their first years of teaching. Conway et al. (2005) contend that new teachers are often afraid to deviate from the norm they find in the school and are afraid to try new things such as using technology. According to Gorder (2008), experienced teachers are more likely to use technology. This can be attributed to the fact that established teachers are more comfortable with the teaching process and more acclimatised to the school culture such that they can experiment with new ideas, unlike new ones who are still trying to get used to teaching and fitting in. Probably this notion could help explain some intriguing findings that have been obtained by studies that showed that new teachers of today, who are believed to be more technology savvy than their predecessors, do not utilise technology in their teaching as would be expected (Allsopp, McHatton, \& Cranston-Gingras, 2009; Lei, 2009).

The current crop of pre-service teachers are what has come to be commonly known as digital natives, describing the generation that has grown up with technology (Vodanovich, Sundaram \& Myers, 2010). Digital natives are often characterised by a high level enthusiasm in using technology (Junco, 2014). This gives a legitimate expectation that they are more likely to use technology in their teaching. However, several studies have found that the majority of these pre-service teachers use various technology resources extensively outside the classroom for their personal use and very minimally in the classroom for teaching. For example, in a study conducted by Lei in 2009 with pre-service teachers to investigate their attitudes, beliefs, and technology experience and expertise, the results indicated a high percentage (80\%) of time spent on social communication, with only about $10 \%$ of that time spent on learning activities. Usage of Web 2.0 technologies was limited to social networking sites and no classroom application. Allsopp et al. (2009), conducted a study to evaluate the effects of a one-to-one laptop initiative meant to systematically integrate technology in an undergraduate special education program. One of the interesting findings from this study was that even though the participants were 
typical undergraduate students who regularly used technologies such as e-mail, text messages, and social networking websites for social interactions, when these students were given group projects to work on outside of class and provided with the same technologies, they did not make use of them. Rather, at the end of the projects students complained that they had difficulties completing the tasks because they did not get enough time to meet face to face with their group members.

Two important observations have been made on the studies conducted on pre-service teachers' use of technology. These are: (a) methodologically; a majority of the studies used a survey instrument to obtain data from participants (Chen, 2008; Yeung, Taylor, Hui, Lam-Chiang, \& Low, 2012), and (b) the studies mostly targeted participants who were doing practicums in colleges/universities not practicing in the field (Liu, 2012; Magliaro, \& Ezeife, 2007). This study contends that even though surveys are an efficient way of collecting data, in order to fully understand the pre-service teachers' use of technology or lack thereof, it would be more informative to observe the participants in the field as they teach. This would enable one to fully appreciate the circumstances under which they operate which probably influence their decision to use or not use technology. To obtain first hand and contextual information on the participants' technology use, this study adopted qualitative approaches; mainly observations and interviews.

\section{Theoretical framework}

This study used the unified theory of acceptance and use of technology (UTAUT) as a conceptual framework to help understand why pre-service teachers would or would not use technology in the delivery of their lessons during teaching practice. UTAUT is a theory formulated by Venkatesh, Morris, Davis and Davis (2003) postulating that acceptance and usage of technology is determined by four main factors:

i. Performance expectancy, defined as the degree to which an individual believes that using the system will help him or her to attain gains in job performance.

ii. Effort expectancy, defined as the degree of ease associated with the use of the system.

iii. Social influence, defined as the degree to which an individual perceives that important others believe he or she should use the new system.

iv. Facilitating conditions, defined as the degree to which an individual believes that an organisational and technical infrastructure exists to support use of the system.

The UTAUT theory holds that the four factors are the main determinants of intention to use technology, and behaviour (Venkatesh et al., 2003). Gender, age, experience, and voluntariness have an impact on how the key constructs result in usage intention and behaviour. Venkatesh and colleagues also considered these variables as influential in the acceptance of information and communications technology.

The UTAUT theory was regarded as suitable for this study because it calls for a holistic analysis of the variables that influence technology adoption by individuals. The factors identified in this theory were found to be relevant to the conditions under which pre-service teachers find themselves when they teach for assessment during teaching practice. So in this situation, this theory facilitated understanding of why pre-service teachers used or did not use technology in the delivery of their lessons. As Straub (2009) stated, technology adoption is a complex and inherently social process and that is why it is important to establish what factors determine the usage of technology by different groups of people.

\section{Research questions}

The research questions that this study sought to answer as guided by the theoretical framework were:

1. To what extent do pre-service teachers use technology in the delivery of their lessons during teaching practice?

2. What are the participants' beliefs in terms of the benefits of using technology to improve learning and teaching?

3. How comfortable are the participants in using technology to deliver their lessons? 
4. Do the participants believe they are expected to use technology in their teaching?

5. How conducive is the environment for technology use during teaching in terms of resource availability and support?

\section{Methodology}

\section{The setting}

This study took place in both junior and senior secondary schools in Botswana. Junior secondary schools offer levels form-one to form-three, while senior ones offer form-four to form-five. The study covered both government and private schools. For government schools, when an initiative was taken to introduce technology in education, all the secondary schools in the country were provided with similar technology resources around the same time, which means they generally face similar challenges concerning the adequacy and state of the resources. Private schools on the other hand are generally better resourced in various elements including technology.

\section{Selection of the schools}

For this study, a list of the schools where students were placed to do their teaching practice was obtained from the teaching practice office which handled all the logistics of students' placements. Stratified sampling was used to select the different schools to ensure a fair representation in the study. The schools were clustered according to urban and rural type of location. Random sampling was then used to pick at least 10 schools from each cluster, making a total of 20 out of the 41 schools that all the students were posted to for their teaching practice.

\section{Participants}

Participants in this study were pre-service teachers who had just completed their coursework and were on teaching practice. After identifying the schools at which the research would be carried out, participating students were selected using random sampling. The students selected to participate in the study were those who were randomly assigned by the university to assess. The researchers in this study were also students' assessors in the teaching practice exercise. A total of 52 pre-service teachers participated in the study from a cohort of 95 students, which was $55 \%$ of the total student population doing teaching practice.

\section{Data collection instruments and procedures}

This study was a qualitative inquiry taking place in the participants' teaching context, thus the methodologies used were meant to interrogate the contextual intricacies at play that influenced their use of technology. Multiple sources of data were used to get a fuller picture and a better understanding of the context in which the teaching was taking place. Data collection strategies used were observations, interviews and document analysis.

\section{Observations}

This study engaged naturalistic observation. As mentioned before, researchers in this study were also students' assessors, so they were able to sit in the classrooms doing the evaluations without the participants knowing that they were also being observed for technology use. The advantage of this technique was that, first, it provided an opportunity to witness first hand whether the participants were using technology or not, therefore, obtaining information that was more reliable when compared to self-reports. Secondly, this covert participation ensured that the participants did not alter their activities for the research.

The observations were semi-structured, however leeway was provided to accommodate any emerging issues as events unfolded during teaching. According to the UTAUT framework, people are more likely to adopt a new system if the necessary resources are readily available and the environment is conducive enough for them to do so. Thus, in this study observations were carried out to assess the environment in which the participants were 
teaching. The observations were specifically paying attention to establishing whether there was any technology used during class and if so, how it was used, the teaching techniques used and the availability of technology resources in individual classes where the lessons were taking place. The ratio of student to computers and the condition of the resources were also observed in the whole school. This helped to establish whether the preservice teachers had an enabling environment to use technology in their teaching. Each participant taught two different subjects and they were observed once for each subject, making a total of two observations per participant. The observations were carried out until the researchers felt they were no longer learning anything new from observing the different lessons.

Interviews

After the second observations, participants were interviewed to get an in-depth understanding of their technology use. The interviews lasted between 10-20 minutes. Interview questions were used as a guide and the questions addressed the four main components of the UTAUT framework, namely performance expectancy, effort expectancy, social influence, and facilitating conditions. Table 1 below presents examples of questions asked in operationalising each construct.

Table 1

UTAUT constructs and questions asked

\begin{tabular}{ll}
\hline UTAUT construct & Questions \\
\hline Performance expectancy & $\begin{array}{l}\text { Do you believe the use of technology would have } \\
\text { improved the delivery of your lesson in any way? } \\
\text { Do you believe the use of technology would have } \\
\text { improved the overall grade for the assessment of } \\
\text { the lessons? Explain. }\end{array}$
\end{tabular}

Effort expectancy

Social influence

Facilitating conditions
On a scale of $1-5$, how comfortable are you with the use of technology?

Do you feel technically confident enough to use technology in the delivery of your lesson? Explain. Do you feel skilled enough to effectively incorporate the use of technology in the lesson in such a way that it would help you achieve the intended goals?

Do you think the school (where you are currently teaching) expects you to use technology in the delivery of your lessons? Yes _ No_ Why do you think so?

Do you think the university expects you to use technology in the delivery of your lessons? Yes No__ Why do you think so?

What can you say about the availability and accessibility of technology resources in your school?

What can you say about the condition of the resources in the school?

Document analysis

The following documents were analysed as an effort to get more understanding about technology use by the pre-service teachers: 
i. The participants' teaching portfolios: These contained all the materials that the students used in their teaching, which included lesson plans, scheme of work, teaching resources, samples of their students' work, grades from previous assessors and their journals. The purpose for this exercise was to look for any evidence of technology integration in their planning.

ii. The assessment instrument: This is the assessment tool that was used by both the university supervisors and the school-based mentors to evaluate the students' teaching. The assessment instrument was deemed an important document as it had potential to influence the way the participants delivered their lessons in their effort to meet the criteria requirements.

\section{Ethical considerations}

In this study, permission was not sought from the participants to observe them for technology use. This was because the intention was to observe whether they would naturally use or not use technology during their teaching and the concern was that informing them may influence their behaviour. However, informed consents were obtained from the participants at the interview stage. At this point, it was revealed to the participants that they had been observed for technology use and asked whether they had objections against that. All the participants observed indicated that they did not have a problem with the observations and consented to the use of the data collected on them through this method.

\section{Data analysis}

The interviews were transcribed and entered into a text document. Information from the observation guides and the analysed documents was also typed into the same document to be read as one piece during coding. The data was then read through and coded, assigning descriptive codes to the information. Themes were then generated from the codes providing answers to the research questions of the study. The analysis of data involved making reference to the literature and the identified constructs in the theoretical framework that guided the study to establish whether the findings of this study corroborated propositions of the framework or whether they differed. This helped to gain an in-depth understanding of the factors that influence the decision to use or not use technology and what other additional factors could be at play in the process of technology integration.

\section{Results of the study}

\section{Demographic information}

A total of 52 pre-service teachers participated in the study, with 35 females and 17 males. The age-range of the participants was 20-29 years with the majority of the participants falling in the 20-24 year age bracket. This was an acceptable representation of the teaching practice students.

\section{Technology use}

The results of this study indicated that the majority of the participants did not use technology during the delivery of their lessons. In fact only $10 \%$ of the participants used technology in their classes. A point worth noting is that almost all teachers who used the technology in their classes were teaching in private schools. Only one teacher from a government school used some type of technology in the form of a cell phone to supplement their lesson. In those instances where technology was used, the teachers mainly used PowerPoint to deliver the lessons. The teachers brought personal laptops which they connected to projectors borrowed from their schools. The presentations involved notes, diagrams, and videos. For those participants who did not use any technology in their classes, an analysis of their portfolios indicated that there was no use of technology in the previous lessons, or any intentions to use it in the upcoming lessons. The predominant teaching style in all the observed lessons was lecturing, with sporadic efforts to engage learners in the lessons through activities such as group work. 


\section{Beliefs in the usefulness of technology to improve learning and teaching}

The majority of the participants in the study stated that they believed that technology was useful in learning and could have enhanced students' understanding through various ways such as attracting their attention, simplifying concepts, saving time, and providing information that is not covered in the textbooks. Below are excerpts from some of the responses from the participants about their beliefs in the usefulness of technology:

- I believe technology would have improved students' learning because they would be able to see things from the computer instead of just imagining, this would help them understand more.

- Technology would improve communication in class as other students express themselves better in writing.

- Technology simply attracts the interest of the students, so you can’t go wrong when using it.

Two participants in the study indicated that they did not believe technology could have improved their lessons in any way. All the participants reported that they believed the use of technology would have enhanced their own performance in terms of improving their teaching, but did not believe it would have improved their grades for teaching practice. The participants said:

- Yes, I believe technology would have improved my teaching, but I do not think it would have changed my marks because I am not being judged on whether I could use technology or not.

- I think even though technology improves teaching, it is something I would prefer to use when I am on my own, not when I am being assessed because I do not trust these old computers in the school, they may refuse to work and that would make me fail.

- Technology is useful, but in terms of making me score higher? I don’t think so.

\section{Comfort levels in using technology to deliver lessons}

During the interviews, participants were asked to rate their technology proficiency levels on a scale of 1-5 (with 5 being very comfortable with using technology tools), and $89 \%$ of them indicated a 4 , while $9 \%$ indicated a 5 , and $2 \%$ a 3 . The participants reported that they felt technically skilled enough to easily use technology resources in their teaching. They stated that they felt the technology training they received from the university through the educational technology course and other courses that involved technology equipped them with sufficient skills to be able to use technology in their teaching. As such, a majority of them indicated high comfort levels in using technology for teaching. The following are some of the participants' quotes regarding their competency in using technology:

- At the university, we are really well equipped to use technology.

- During our study, we were taught how to use technology and even given opportunities to practice how to use it in the lessons; we prepared lesson plans and made presentations.

- I am fully confident I can use technology during a lesson; we have been given enough skill and knowledge.

\section{Expectations to use technology in teaching}

In terms of the expectations placed upon the pre-service teachers to use technology, this study found that generally the participants did not believe that they were required to use technology during their teaching practice. In response to the question whether they believed the university expected them to use the technology in their teaching, most of the participants gave a double-sided answer. The participants indicated that on one hand they believed the university expected them to use technology because it was compulsory for them to take a technology training course during their studies. On the other hand, they did not believe that they were expected to use technology in their teaching because the criteria used to evaluate them during teaching practice did not include any assessment of technology use. The participants said: 
- I believe the university wants us to use technology because they teach us how to use technology while training, but I do not think they care if we don't use it during practice.

- We take a compulsory course on technology use at the university, however our assessment does not include technology use.

- Yes, we were taught how to make learning interesting and easy through the use of technology, but when we get to the field, this is not an emphasis, no one has ever said to me you did not use technology so you will fail.

On the question whether they thought the schools (where they were teaching) expected them to use technology, the majority of participants said no and the reasons advanced were:

- There are no available resources in the classrooms to use technology.

- There is nothing in place to encourage us to use technology when the mentor teachers assess us, they do not ask about technology. I believe most of the teachers themselves in the school, do not know how to use technology in teaching.

Most of the participants in the study reported that they believed the schools also did not expect them to use technology because they used the same assessment tool from the university to grade their performance during teaching. The pre-service teachers also reported that during their own class observations, they did not witness any use of technology by the mentor teachers as one participant stated, "In all my observations, I did not see any of my mentor teachers using technology so it looks like technology is not a big deal really". Some participants also indicated that they had too much material to cover within limited time and they felt including technology would delay them. One teacher said, "We have a lot of objectives to cover in a lesson and using technology itself requires time, so this may disadvantage you when you are being assessed." Another one said "Yes technology is useful but personally I feel it would have made me fail because it takes a lot of time so I may fail to cover all objectives”. The participants also stated that the schools did not provide any kind of support or incentive to the use of technology in learning. An analysis of the assessment criteria used to evaluate the preservice teachers revealed that there was no specific item assessing the use of technology.

\section{Provision of a conducive environment to use technology}

Most of the participants indicated that the environment in the schools was not conducive for technology use because there were no readily available resources in the classrooms to use technology with the students. All the schools in the study had computers which were located in the computer labs. However it was revealed that for the most part the labs were used by the computer studies classes, leaving limited allowance for other subjects to use it. When asked whether they had ever made any attempts to make arrangements to take their students to the computer lab, most participants answered in the negative. The participants also reported that the schools did not have enough projectors that they could at least use with laptops in their classes, in fact some reported that the teaching rooms themselves were not conducive for technology use. One student summed this sentiment by saying, "Electric sockets in the classrooms are not working. There is the tedious process of booking the lab and even then students have to share computers and time is limited to use technology".

Participants in private schools indicated a slight satisfaction with the technology resources in the schools. One participant summed their sentiment in saying, "Look, things here are a bit better than in government schools because even if you can't get the lab if you have a laptop you can use a projector to teach in your class. But really things are not yet there, there is still more that needs to be done in providing adequate resources”.

The study also indicated that there was no significant difference in the way technology was used or not used in relation to the participants' gender, age and experience, especially that the majority of the participants did not use technology in their teaching. The total number of participants who used technology in the study was too small to make any meaningful comparisons. Of the 5 participants who used technology, 3 were female, while 2 were male. In terms of age, 3 belonged to the 20-24 age range, while 2 belonged to the 25-29 range. Perhaps 
the only variable that had a slightly notable variance was teaching experience, which showed that from the 5 technology using teachers, 4 had teaching experience, and 1 had no teaching experience.

\section{Discussion}

This study like many other research findings indicated that technology was greatly under-used by pre-service teachers. However, the majority of past studies have identified inadequate training as one of the main reasons why new teachers were reluctant to use technology in their classes (Gülbahar, 2008; Liu, 2012). In this study, the majority of the participants reported that they felt sufficiently trained and confident enough to use technology in the delivery of their lessons. The study found that the main reason they were not using technology was because they did not see it as part of the requirements from people who matter (their mentors and university supervisors) for them to pass their teaching practice. According to the UTAUT model, social influence is a very important pre-cursor of whether people adopt a new system or not. In the context of this study, the opinions of the assessors were very crucial because these were the people who ultimately decided whether the pre-service teachers passed their teaching practice or not. Therefore, if these pre-service teachers perceived that technology was not part of the expectations of the assessors, then they would not be inclined to use it in their lessons even if they had the skills to do so.

The perceived non-expectancy to use technology by the pre-service teachers in this study was perpetuated by the fact that the mentor teachers themselves did not use technology in their teaching. Mentoring plays a very significant role in influencing new teachers to use technology as they look up to their mentors to model technology use. Studies have shown that training programs that have a technology mentoring aspect report positive results on the influence of mentorship in promoting technology use by practicing teachers (Judge \& O’Bannon, 2007; Liu, 2012). This absence of technology role modelling and the perceived lack of expectations on the pre-service teachers to use technology sent a strong message to the pre-service teachers that technology was not part of the school culture, therefore this influenced their decision to not use it.

Participants in this study reported that they believed technology was useful in improving students' learning, yet they did not use it in their lessons, thus displaying a mismatch between what the teachers believed and their actual practices. This finding further highlights the complexities of the relationship between the teachers' beliefs and their practices when it comes to technology use. The results also suggested that the pre-service teachers were more concerned with their performance than the students' achievement. Having noted that technology was not exactly a requirement for them to be considered to be doing a good job, it is clear the participants were not motivated to use it. This is consistent with the propositions of the UTAUT which postulate that people would be more inclined to use a system if they believe that it will help them improve their job performance. This was even truer in this study because the pre-service teachers' main goal was to pass their teaching practice and may not have been willing to engage in "risk-taking behaviours" as Yeung et al. (2012; p. 868) put it, especially if they do not believe it will add any value to their ultimate goal. This also brings to question the whole notion of grading students on teaching practice. Some studies have reported that grading has a detrimental effect on students' learning because it somehow limits students' interest and learning practices to those activities that they believe would matter grade-wise (Kohn, 2011).

This study also showed that the way the technology was used by those who integrated it, was at a very rudimentary level, not in a manner that could promote desired twenty-first century skills such as critical thinking and problem solving. This also concurs with previous studies that even if new teachers use technology, they use it at a very basic level that does not maximise the potential of technology in learning (De Santis \& Rotigel, 2014). This study also indicated that the predominant teaching methods used by the participants were traditional teaching practices, therefore, as the literature has denoted, it was not surprising that there was limited technology use by the pre-service teachers.

Another major reason reported by participants for not using technology was lack of adequate resources. Research has shown that when resources are readily available to teachers that increases their chances of integrating the tools in their lessons (Yeung et al., 2012). In this study, the almost exclusive use of technology 
by the pre-service teachers located in private schools, which were reported to be better resourced than their government counterparts, points to the possibility of improved technology use by practicing teachers if more resources were made readily available to them.

Lastly, according to the UTAUT, gender, age, and experience, impact the results of the key constructs in terms of usage intention and behaviour. In this study, these variables did not seem to have influence on technology use by the pre-service teachers, as there were no significant differences across the participants' ages and teaching experiences. In terms of gender, studies have shown that males and females are mostly at par in their technology use (Magliaro \& Ezeife 2007; Yeung, et al., 2012). This study also adds to the argument that gender has become a non-issue in technology use.

\section{Conclusion}

This study showed that building a culture of technology use by practicing teachers is a complex task that requires a multi-faceted approach which takes into consideration various elements that influence their decision to use or not use it. The study showed that even when teachers are adequately trained to use technology, it is still not a guarantee that they would use it. As this study has demonstrated, it is equally important to provide facilitating conditions that would promote the integration of technology tools in learning. These conditions take various forms both physical and theoretical. Provision of adequate resources is an essential element of any technology integration program. However, this needs to be accompanied by a supportive culture and a facilitating organisational structure that supports the use of technology.

\section{Implications}

This study highlights the shortcomings of running isolated technology use initiatives which are not integrated in the broader practice of training and teaching. The study made it clear that at the tertiary education level, there is a need to address technology use beyond the classrooms to ensure that this element is taken into consideration when evaluating the whole process of teaching by pre-service teachers, so that it becomes part of their toolkit right from the beginning. Training and practice should send the same message to the students about the importance of technology in learning. Therefore, this study recommends that technology proficiency indicators be included in the assessment criteria used to evaluate students in teaching practice. This will motivate the preservice teachers to make more efforts to incorporate technology in their lessons.

The results of this study also suggest that there is a need to develop a strong link between tertiary level education and what is happening in the schools to enable pre-service teachers to effectively put into practice what they learned. This implies making changes such as reviewing the school curriculum and assessment procedures to ensure that they support technology use. As Lim and Khine (2006) note that sometimes even if teachers have the technology skills and knowledge, they still gravitate back towards non-technology use and its associated traditional teaching pedagogies because they believe this mode is more efficient in covering the set curriculum. From this study, it is clear that even though in essence the schools have decided to implement technology, there is still more that needs to be done to change actual behaviours and practices, as Lim and Khine have noted.

This study identified lack of resources as one of the hindering factors that discourage pre-service teachers to use technology. Various initiatives have been taken by institutions in similar situations which have resulted in cost effective ways to broaden technology access to the users (Mader, 2014; Watters, 2012). Therefore, decision makers need to craft resource policies that would ensure wider and more equitable access to technology resources so that teachers feel encouraged to adopt it in their lessons. One such way could be through the provision of movable resources (projectors, laptops, tablets) that can be used in the classrooms so that even if lessons cannot be held in the computer labs, teachers can have access to some form of technology they can use with their students. 


\section{Further Research}

This study looked at technology use by pre-service teachers when they were at the schools doing teaching practice, which subsequently meant seeking an understanding of technology use by the teachers in the respective schools so as to appreciate the context in which the student teachers operated. However, it is equally important to understand the context in which the students were trained for their teaching. As Siegel (1995) says, teachers teach the way they were taught, therefore it is important to conduct research among university instructors to find out if they use technology in the delivery of their lessons as this has implication on how the pre-service teachers perceive the issue of technology in learning. The results of such a study would contribute to the development of a comprehensive strategy that is meant to ensure that technology use is addressed at all levels.

\section{References}

Albirini, A. (2006). Teachers' attitudes toward information and communication technologies: The case of Syrian EFL teachers. Computers \& Education, 47(4), 373-398. http://dx.doi.org/10.1016/j.compedu.2004.10.013

Allan, H. K. Y., Law, N., \& Wong, K. C. (2003). ICT implementation and school leadership: Case studies of ICT integration in teaching and learning. Journal of Educational Administration, 41(2), 158-170. http://dx.doi.org/10.1108/09578230310464666

Allsopp, D. H., McHatton, P. A., \& Cranston-Gingras, A. (2009). Examining perceptions of systematic integration of instructional technology in a teacher education program: Teacher education and special education: The Journal of the Teacher Education Division of the Council for Exceptional Children, 32(4), 337-350. http://dx.doi.org/10.1177/0888406409346144

Almekhlafi, A. G., \& Almeqdadi, F. A. (2010). Teachers' perceptions of technology integration in the United Arab Emirates school classrooms. Educational Technology \& Society, 13(1), 165-175.

Al-Ruz, J. A., \& Khasawneh, S. (2011). Jordanian pre-service teachers' and technology integration: A human resource development approach. Educational Technology \& Society, 14(4), 77-87.

Anderson, S. E, \& Maniger, R. M. (2007). Pre-service teachers` abilities, beliefs and intentions regarding technology integration. Journal of Educational Computing Research, 37(2), 151-172. http://dx.doi.org/10.2190/H1M8-562W-18J1-634P

Bandura, A. (1963). Social learning and personality development. New York, NY: Holt, Rinehart, and Winston.

Chen, H.-C. (2008). Why do teachers not practice what they believe regarding technology integration? The Journal of Education Research, 102(1), 65-75. http://dx.doi.org/10.3200/JOER.102.1.65-75

Conway, C., Micheel-Mays, C., \& Micheel-Mays, L. (2005). A narrative study of student teaching and the first year of teaching: Common issues and struggles. Bulletin of the Council for Research in Music Education, 165, 65-77.

Dawson, V. (2008). Use of information and communication technology by early career science teachers in Western Australia. International Journal of Science Education, 30(2), 203-219. http://dx.doi.org/10.1080/09500690601175551

DeSantis, J. D., \& Rotigel, J. V. (2014). Evolving a technology integration ethos: Technology habits of preservice and in-service teachers. Journal of Instructional Pedagogies, 14. Retrieved from http://www.aabri.com/manuscripts/141850.pdf

Ertmer, P. A. (2005). Teacher pedagogical beliefs: The final frontier in our quest for technology integration? Educational Technology Research and Development, 53(4), 25-39. http://dx.doi.org/10.1007/BF02504683

Gorder, L. M. (2008). A study of teacher perceptions of instructional technology integration in the classroom. Delta Pi Epsilon Journal, 50(2), 63-76.

Gülbahar, Y. (2008). ICT usage in higher education: A case study on pre-service teachers and instructors. The Turkish Online Journal of Educational Technology, 7(1) Article 3. Retrieved from http://www.tojet.net/articles/v7i1/713.pdf

Hargittai, E., \& Shafer, S. (2006). Differences in actual and perceived online skills: The role of gender. Social Science Quarterly, 87(2), 432-448. http://dx.doi.org/10.1111/j.1540-6237.2006.00389.x 
Inan, F. A., \& Lowther, D. L. (2010). Factors affecting technology integration in K - 12 classrooms: A path model. Educational Technology Research and Development, 58(1), 37-154.

Judge, S., \& O’Bannon, B. (2007). Integrating technology into field-based experiences: A model that fosters change. Computers in Human Behaviour, 23(1), 286-302. http://dx.doi.org/10.1016/j.chb.2004.10.013

Junco, R. (2014). iSpy: Seeing what students really do online. Learning, Media and Technology, 39(1), 75-89. http://dx.doi.org/10.1080/17439884.2013.771782

Kelly-McHale, J. (2013). The influence of music teacher beliefs and practices on the expression of musical identity in an elementary general music classroom. Journal of Research in Music Education, 61(2), 195216. http://dx.doi.org/10.1177/0022429413485439

Koh, J. H. L., \& Frick, T. W. (2009). Instructor and student classroom interactions during technology skills instruction for facilitating pre-service teachers' computer self-efficacy. Journal of Educational Computing Research, 40(2), 211-228. http://dx.doi.org/10.2190/EC.40.2.d

Kohn, A. (2011). The case against grades. Educational Leadership, 69(3), 28-33. Retrieved from http://www.alfiekohn.org/article/case-grades/

Kong, S. C., Chan, T.-W., Griffin, P., Hoppe, U., Huang, R., Kinshuk ... Yu, S. (2014). E-learning in school education in the coming 10 Years for developing 21st century skills: Critical research issues and policy implications. Educational Technology \& Society, 17(1), 70-78.

Lei, J. (2009). Digital natives as pre-service teachers: What technology preparation is needed for? Journal of Computing in Teacher Education, 25(3), 87-97.

Lim, C. P., \& Khine, M. S. (2006). Managing teachers’ barriers to ICT integration in Singapore. Journal of Technology and Teacher Education, 14(1), 97-125.

Liu, S. (2012). A multivariate model of factors influencing technology use by pre-service teachers during practice teaching. Educational Technology \& Society, 15(4), 137-149.

Mader, J. (2014). In Mississippi schools, access to technology lacking, uneven. The Hechinger Report. Teachers College at Columbia University. Retrieved from http://hechingerreport.org/content/mississippischools-access-technology-lacking-uneven_16660/

Magliaro, J., \& Ezeife, A. N. (2007). Pre-service teachers’ preparedness to integrate computer technology into the curriculum. Canadian Journal of Learning and Technology, 33(3). Retrieved from http://www.cjlt.ca/index.php/cjlt/article/view/163/153

Murley, L. D., Jukes, P., \& Stobaugh, R. (2013). Raising expectations for pre-service teacher use of technology. International Journal of Humanities and Social Science, 3(14).

Niederhauser, D. S., \& Perkmen, S. (2010). Beyond self-efficacy: Measuring pre-service teachers' instructional technology outcome expectations. Computers in Human Behaviour, 26(3), 436-442. http://dx.doi.org/10.1016/j.chb.2009.12.002

Nishino, T. (2012). Modeling teacher beliefs and practices in context: A multimethods approach. The Modern Language Journal, 96(3), 380-399. http://dx.doi.org/10.1111/j.1540-4781.2012.01364.x

Oblinger, D. G., \& Oblinger, J. L. (2005). Introduction. In D. G. Oblinger \& J. L. Oblinger (Eds) Educating the net generation (1.1-1.5). Educause. Retrieved from www.educause.edu/educatingthenetgen/

Pelgrum, W. J., \& Law, N. (2003). ICT in education around the world: Trends, problems and prospects. Retrieved from http://unesdoc.unesco.org/images/0013/001362/136281e.pdf

Prenksy, M. (2001). Digital natives, digital immigrants. On the Horizon, 9(5), 1-6. http://dx.doi.org/10.1108/10748120110424816

Rosenthal, I. G. (1999). New teachers and technology: Are they prepared? Technology and Learning, 19(8), $1-2$.

Scheeler, M. C. (2008). Generalising effective teaching skills: The missing link in teacher preparation. Journal of Educational Technology, 17(2), 145-159. http://dx.doi.org/10.1007/s10864-007-9051-0

Siegel, J. (1995). The state of teacher training. Electronic Learning, 14(8), 43-53.

Straub, E. (2009). Understanding technology adoption: Theory and future directions for informal learning. Review of Educational Research, 79(2), 625-649. http://dx.doi.org/10.3102/0034654308325896

Teo, T. (2008). Pre-service teachers' attitudes towards computer use: A Singapore survey. Australasian Journal of Educational Technology, 24(4), 413-424.

Venkatesh, V., Morris, M., Davis, G. B., \& Davis, F. D. (2003), User acceptance of Information Technology: Toward a unified view, MIS Quarterly, 27(3), 425-478. 
Verloop, N., Van Driel, J., \& Meijer, P. (2001). Teacher knowledge and the knowledge base of teaching. Teacher Professionalism, International Journal of Educational Research, 35(5), 441-461. http://dx.doi.org/10.1016/s0883-0355(02)00003-4

Vodanovich, S., Sundaram, D. \& Myers, M. (2010). Research commentary: Digital natives and ubiquitous information systems. Information Systems Research, 21(4), 711-723. http://dx.doi.org/10.1287/isre.1100.0324

Wachira, P., \& Keengwe, J. (2011). Technology integration barriers: Urban school mathematics teachers' perspectives. Journal of Science Education and Technology, 20(1), 17-25. http://dx.doi.org/10.1007/s10956-010-9230-y

Wang, L. J., \& Wu, Y. T. (2015). The exploration of elementary school teachers' Internet self-efficacy and information commitments: A study in Taiwan. Educational Technology \& Society, 18(1), 211-222.

Watters, A. (2012). What tech in schools really looks like? The digital shift, library journal. Retrieved from http://www.thedigitalshift.com/2012/04/digital-divide/what-tech-in-schools-really-looks-like/

Yeung, A. S., Taylor, P. G., Hui, C., Lam-Chiang, A. C., \& Low, E.-L. (2012). Mandatory use of technology in teaching: Who cares and so what? British Journal of Educational Technology, 43(6), 859-870. http://dx.doi.org/10.1111/j.1467-8535.2011.01253.x

Yüksel, G., \& Kavanoz, S. (2011). In search of pre-service EFL certificate teachers’ attitudes towards technology. Procedia Computer Science, 3, 666-671. http://dx.doi.org/10.1016/j.procs.2010.12.111

Corresponding author: Tshepo Batane, batane@mopipi.ub.bw

Australasian Journal of Educational Technology (c) 2017.

Please cite as: Batane, T., \& Ngwako, A. (2017). Technology use by pre-service teachers during teaching practice: Are new teachers embracing technology right away in their first teaching experience? Australasian Journal of Educational Technology, 33(1), 48-61. https://doi.org/10.14742/ajet.2299 